Artículo de Sociología 



\title{
Aproximación sociológica de la construcción de imaginarios sociales de niños y niñas del barrio Niño Jesús de Praga en torno a procesos de socialización en la familia, el grupo de iguales y el barrio'
}

\section{Sociological approach to the construction of social imaginary children from the Infant Jesus of Prague neighborhood around socialization processes in the family, the peer group and neighborhood}

\author{
Claudia Mercedes Jiménez Garcés²
}

\begin{abstract}
Resumen
El presente artículo muestra los hallazgos del proceso investigativo desarrollado en 2005 denominado: Imaginarios del niño y la niña residentes en el barrio Niño Jesús de Praga con respecto a la familia, su grupo social de iguales y el barrio, como elemento de construcción de alternativas para la satisfacción de necesidades desde y para la población infantil. Desde el enfoque crítico social reflexiona sobre la construcción de imaginarios sociales a partir de formas particulares de socialización de niños y niñas en tres escenarios: familia, grupo de iguales y barrio, con el fin de generar estrategias de mejoramiento comunitario a las problemáticas sociales evidenciadas en el barrio a partir de la definición de niño y niña como actor social de su entorno. El artículo evidencia dinámicas de socialización en contextos de vulnerabilidad y problemáticas sociales de la población infantil e identifica elementos que les permiten construir sus imaginarios.
\end{abstract}

Palabras claves: barrio, familia, grupo de iguales, imaginarios y socialización

\begin{abstract}
This article shows the conclusions of the investigation developed in 2005,called: Imaginarios del niño y la niña residentes en el barrio Niño Jesús de Praga con respecto a la familia, su grupo social de iguales y el barrio, como elemento de construcción de alternativas para la satisfacción de necesidades desde y para la población infantil From a critical approach, the article review the construction of social imageries of the childhood from their particular forms of socialization in three scenarios: family, group of peers and neighborhood, in order to generate strategies of community improvement to social problems evidenced in the childhood of that neighborhood, from the definition of boy and girl as a social actor of their environment. The article evidence some dynamics of socialization in contexts of vulnerability and social problems of childhood and identify elements that allow them to build their social imaginary.
\end{abstract}

Words key: neighborhood, family, peer group, imaginary and socialization.

Recibido: 1 de noviembre de 2012 Aceptado: 14 de febrero de 2013

1 La investigación es una coautoría con el sociólogo Andrés Fernando Chamarro, realizada en el año 2005.

2 Socióloga Universidad de Nariño, especialista en Educación, Cultura y Política de la Universidad Nacional Abierta y a Distancia (UNAD), maestrante en Género, Sociedad y Políticas de la Facultad de Ciencias Sociales de la Universidad de Buenos Aires. Docente de la Universidad Nacional Abierta y a Distancia. E-mail: claudia.jimenez@unad.edu.co 


\section{A manera de introducción}

La investigación que muestra los hallazgos esbozados en el presente artículo se propuso como objetivo central: comprender el imaginario del niño y la niña en sus relaciones sociales de carácter familiar, grupal y barrial para construir herramientas desde y para la población infantil. Se desarrolló con base en las siguientes fines: caracterizar socioculturalmente a la población infantil; indagar cómo son los procesos de socialización de los niños y niñas desde la familia, el grupo de iguales y el vecindario; comprender el imaginario que la población infantil posee sobre su familia, grupo de iguales y barrio; y establecer, desde el imaginario del niño y la niña, herramientas que permitan mejorar sus condiciones de vida. Este proceso fue sustentado en el método crítico social, bajo la modalidad de la investigación participativa.

Para comprender cómo los niños y niñas construyen sus imaginarios sociales, es importante indagar la definición de su papel en la sociedad a partir de su participación en contextos particulares y cómo estos escenarios influyen en sus percepciones del mundo. Para esto se recurre a Martínez y Saurí (2004), quienes ponen en duda algunos supuestos y paradigmas sobre la niñez en momentos concretos de la historia; así, encuentran contradicciones sociales e históricas, tales como su condición de no ser y como propiedad privada, frente al reconocimiento de los derechos del niño, pero que a la vez son sujetos que perpetúan su sometimiento al adulto, el cual limita su participación. La segunda contradicción es ver a la infancia como lo que ya son y como patrimonio público, con una participación protagónica que es vista como derecho social y político. De esta manera, la infancia puede cumplir el papel de sujeto social capaz de contribuir en la formulación de estrategias encaminadas a la transformación de la realidad; es decir, alcanza el estatus de sujeto social, económico y político.

La infancia aparece como categoría en la modernidad, y se la caracteriza por contener elementos para comprender el mundo $y$ transformar el submundo objetivo (Luhman y Beck; citados por Wagner, 1987). Esta categoría se materializa con políticas estatales y comunitarias que se reflejan y moldean en los procesos de socialización, que son los que configuran las actuaciones sociales de los niños y niñas, es decir, permean las formas como ven y construyen su mundo cotidiano dentro de una dinámica de cohesión cultural, pero también desde las posibilidades detransformación social.El concepto de imaginarios (Castoriadis, 2002) es aquella representación simbólica de la realidad, donde también se entrecruzan fisuras, antagonismos y contradicciones de las lecturas que el sujeto hace de su sociedad. Para el caso de la investigación fue indispensable descubrir, desde los roles construidos y apropiados socialmente por los niños y las niñas, los elementos que representan imaginarios sociales con el fin de generar alternativas de solución para las problemáticas sociales de su contexto, desde sus exigencias particulares y su punto de vista.

\section{Metodología}

El trabajo se fundamenta en la metodología de la investigación participante, desde un enfoque crítico social, que por su flexibilidad permitió combinar varios métodos (etnografía, investigación histórica y técnicas de planificación participativa). La muestra está conformada por veinte niños y niñas entre los 5 y doce 12 años, pertenecientes al barrio Niño Jesús de Praga de la ciudad de San Juan de Pasto (Nariño, Colombia). Según los planes de ordenamiento territorial, esta población está ubicada en una zona urbana de vulnerabilidad y riesgo social, debido a sus altos índices de maltrato infantil, trabajo infantil, consumodesustanciaspsicoactivas, desnutrición, embarazos prematuros, entre otros. El proceso metodológico, basado en las propuestas de Bonilla y Rodríguez (1997), permitió el manejo de categorías cualitativas. Desde la lógica crítica social, se aplicaron los siguientes pasos: primero, recolección de datos mediante el acercamiento a la población de estudio, con técnicas como 
la observación participante y conversaciones informales; segundo, generación de lazos de confianza y participación, gracias a la técnica anterior, y recolección de testimonios, y tercero, recolección de información sobre su papel en escenarios de interacción, con la aplicación de técnicas basadas en juegos compartidos y creados espontáneamente por los niños y niñas como parte de su vida cotidiana. También fueron relevantes las visitas dirigidas por los niños y niñas a lugares de su preferencia dentro y fuera del barrio. Con los datos obtenidos se logró identificar, analizar, interpretar y comprender los imaginarios construidos por los niños para su entendimiento del mundo.

\section{Resultados}

\section{Escenarios para la construcción de imaginarios: procesos de socialización}

Se define como escenarios los espacios sociales y simbólicos mediante los cuales los individuos adquieren formas de interpretar el mundo y de representar las dinámicas de cohesión cultural, pero también de construir procesos de transformación. Los escenarios se evidencian en las estructuras sociales de la vida cotidiana. Para nuestro caso se determinan tres escenarios: la familia, como contexto primario de socialización; el grupo de iguales como el secundario y el barrio como el tercero; según lo exponen los fundamentos del funcionalismo parsonsiano.

La socialización en el escenario familiar de los niños y las niñas del barrio Niño Jesús de Praga se desarrolla en un entorno de abandono físico y afectivo por parte de sus padres y familiares, sumado a acciones de agresividad que se desprenden de las lógicas familiares, grupales y barriales propias del contexto. Existe en ello un proceso de subjetivación que se construye en la socialización y que establece un diálogo intersubjetivo con las perspectivas particulares de los niños y niñas. Una de las formas de subjetividad de la población infantil se representa en el rechazo hacia estos comportamientos y actitudes cotidianas de su entorno como lo son, por ejemplo, el encierro de niños menores de 5 años en las casas mientras los padres realizan labores de reciclaje. Este rechazo funda elementos simbólicos sobre la determinación de posibles soluciones a las problemáticas sociales barriales, que da por sentado la articulación entre familia, grupos de iguales y barrio; es decir, que la interpretación de los escenarios es una correlación entre las manifestaciones compartidas y descubiertas por los niños y niñas.

La familia, que funcionalmente es una de las principales instituciones socializadoras del niño y la niña y que permite asimilar las pautas de comportamiento, leyes y normas que la sociedad impone, es, además, un escenario de influencia del medio social, colectivo y comunitario. Para los niños la familia establece un puente en doble vía: por un lado, lo involucra hacia lo privado, y por el otro, lo inscribe en lo público. Por esta razón, la familia debe comprenderse como un subsistema "cuyos vínculos se basan en relaciones de parentesco fundados en lazos biológicos y sociales, con funciones específicas para cada uno de sus miembros y con una función más o menos claramente determinada en un sistema social" (Páez, 1984: 23).

La familia de la niñez estudiada se ubica en un espacio urbano marginal, y se caracteriza por su estructura monoparental, donde la madre, el padre o figuras sustitutas como abuelos y tíos asumen el cuidado y crianza. Esta clase de familia presenta relaciones inestables, embarazos a temprana edad, bajos niveles de educación, necesidades básicas insatisfechas, violencia intrafamiliar y un alto número de niños y niñas por familia, donde además irrumpen figuras como el padrastro o la madrastra. Para Gutiérrez (2005) este tipo de familias son la consecuencia de las dinámicas de la sociedad actual, que se ve golpeada por las políticas estatales, pero también por elementos socioculturales, como la religión. En el caso del barrio Niño Jesús de Praga, su tipología es la de familias incompletas: "La mencionada característica actual de profunda inestabilidad familiar, ha dado origen a la familia 
incompleta, que admite diversas modalidades en su expresión y procede de diversas coyunturas individuales o sociales" (Gutiérrez, 2005: 10).

Esta circunstancia genera un cambio en los roles tanto de los hombres como de las mujeres, quienes deben asumir las tareas ya sea de la figura materna como de la paterna, dependiendo de la ausencia de una de las figuras. Esta monodependencia hace que las familias superpongan las necesidades laborales sobre lo afectivo, con un efecto claro en la descomposición familiar, el abandono del cuidado de los niños y las niñas y la transformación de los roles infantiles a roles adultos, como trabajar, cuidar de los pequeños y realizar tareas domésticas, independientemente del género.

Como consecuencia de ello existen altos niveles de deserción escolar, de vinculación de niños en calle $y$, por ende, en riesgo de consumo de sustancias psicoactivas, de participación en el comercio sexual o de ser explotados en actividades laborales. La imagen de la Fotografía 1 muestra las condiciones de vida de los menores, en este caso, el niño realiza actividades domésticas como la preparación de alimentos para su familia (cena), obligación que debía ser realizada después de sus responsabilidades escolares. El niño tiene la edad de 5 años, vive con su padre, madrastra, hermanos y abuela paterna.

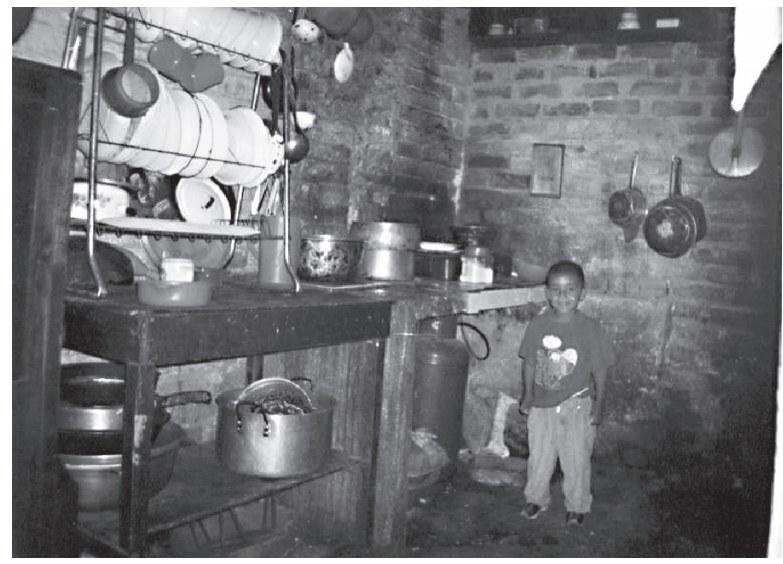

Fotografía 1. Labores domésticas en infantes. Fuente: archivo de investigación.
Los procesos de socialización están atados al contexto social donde se desarrollan, proponen y se imponen las configuraciones de dinámicas familiares particulares. Para el caso de estudio, el núcleo familiar se encuentra influenciado por violencia, drogadicción, agresión e inestabilidad social y cultural. En este escenario los mecanismos de socialización están cargados de una "doble mirada": por un lado, se basan en el castigo físico y verbal, pero, por el otro, se proyectan valores como el respeto, la ayuda mutua y la responsabilidad. Esta complejidad es latente en los comportamientos de los niños y las niñas, quienes asumen un estilo de vida infantil con "mentalidad" adulta. Es especial, los estilos de vida del barrio los roles impuestos a los niños se caracterizan por responsabilidades domésticas y laborales, determinadas por actuaciones adultas.

Esta participación del menor en el mundo adulto de lo público y lo privado revela que en los procesos de socialización los infantes experimentan cohesiones culturales que nacen en la agresión, las cuales generan manifestaciones de rechazo. En la Fotografía 2 un niño de 7 años representa su definición de familia. Como se aprecia, el menor manifiesta la relación que ha establecido con lo público y privado, la cual está mediada por la agresión simbólica de su exterior. Más aún, otras interpretaciones nos dirán que es una forma de protección, en medio de un espacio ambiental armónico visible.

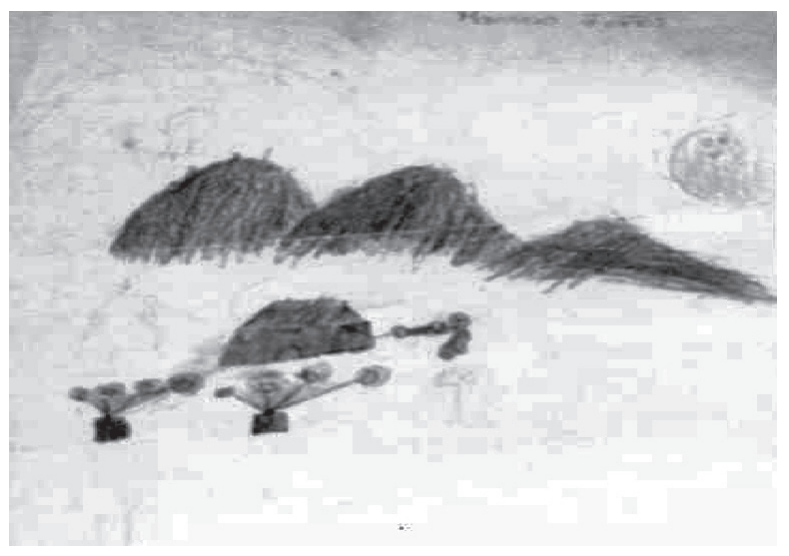

Fotografía 2. Dibujo infantil de un niño disparando a su casa. Fuente: archivo de investigación. 
El grupo de iguales, segundo escenario de socialización, se conforma desde las edades, las relaciones de género y los gustos. Según Elizabeth Horlck (1982:279) existen tres tipos de compañeros: a) los asociativos, personas que satisfacen las necesidades de compañía y que el niño y la niña observan; b) compañeros de juego, que se presentan entre grupo de iguales en género y edad, y con quienes se comparte actividades agradables; c) los amigos, son compañeros con los cuales se generan procesos propios de comunicación, intercambiando ideas, confidencias, concejos y lanzando críticas. Es en este escenario, donde el juego es una de las principales construcciones colectivas de sus roles y de sus representaciones sobre la comprensión del barrio a partir de la influencia del medio, en la investigación se definió como su territorio de encuentro, de espacio para su desarrollo como sujetos sociales y como un lugar para ser recuperado. En este sentido, los juegos tradicionales, como las canicas, saltar tapias, la semana o el avioncito se convierten en los medios de expresión más sentidos y representativos, reforzado por su interés en buscar compañía y compartir un momento de esparcimiento. Se encontró que en el juego los infantes son capaces de imponer reglas que van en pro de la solidaridad, con el derecho a ser tenidos en cuenta. Se podría afirmar, entonces, que el aspecto de mayor influencia en el proceso de socialización del niño y la niña con su grupo de iguales es el juego, que es una construcción colectiva y simbólica que permite desde relación afectiva y comprometida, asimilar, proyectar y vincularse a una vida comunitaria y social armónica, la cual se asienta en formaciones sociales basadas en normas, leyes y pautas de comportamiento que hacen posible una sana convivencia social. En relación a esto, vale la pena citar la percepción de la comunidad a partir de lo expresado por una de las líderes del barrio: "Ios niños cuando juegan son como mariposas en medio de las flores". Esto muestra la importancia de tal actividad en la construcción social del grupo de iguales, pero también, que se convierte en un espacio de reconstrucción del tejido social y de las emociones compartidas.
En el imaginario del niño y la niña su grupo de iguales es un escenario para compartir su vida y construir su mundo sin discriminación o coerción: este otro mundo no es ajeno a la realidad, sino una interpretación diferente, con unos significados y significantes particulares, lo que podría entenderse como la necesidad de encontrarse con ese otro que se niega en el hogar.

Por otra parte, para el niño y la niña el barrio representa su territorio, el cual define sus fronteras simbólicas y ambientales, les brinda conciencia frente a lo colectivo y la identificación de su participación y la apropiación que tienen del vecindario. Este territorio, que asumen como propio, les ha generado criterios de identidad, que se manifiestan, por ejemplo, en el rechazo a los drogadictos: "nuestro barrio es hermoso, pero es mejor si se van esos drogos", afirma un grupo de niños entre los 5 y 7 años. Frente al barrio como escenario, otras de las prácticas sociales que influyen como elemento socializador de los niños y niñas es la religión, que no solo definió la razón de ser del barrio (de allí su nombre gracias a la influencia de un grupo de religiosos para su fundación), sino que son una gran parte de las creencias socialmente compartidas por los pobladores. Lo que en el escenario barrial convierte la vida de los niños en una contradicción, quizá armónica, que estimula el aprendizaje de principios éticos y morales, propios de la religión católica, frente a las prácticas cotidianas de comunicación basadas en la violencia física y verbal.

La Fotografía 3 es un mapa parlante construido por los grupos focales, el cual se orientó a partir de la descripción de su barrio. Esta simbolización habla de la definición de las problemáticas sociales que los niños sufren en su vida cotidiana. Según el grupo focal que elaboró esta imagen, las zonas coloreadas con amarillo representan las calles despavimentadas del barrio, donde se realizan tanto las peleas como el consumo de sustancias psicoactivas. Las manchas de color verde reflejan el parque como lugar significativo para ellos, puesto que 
es donde realizan actividades lúdicas o juegos con su grupo de iguales, pero al tiempo es el lugar donde se presentan delitos menores, como el atraco y expendio de drogas. El color rojo, las muertes de los pandilleros y los drogadictos. Esta configuración de barrio, reconoce las tensiones que se presentan y las fisuras sobre las cuales los niños y niñas generan sus procesos de convivencia y de necesidades por configurar un lugar propio, un lugar desde lo identitario, un lugar para el bienestar y la convivencia.

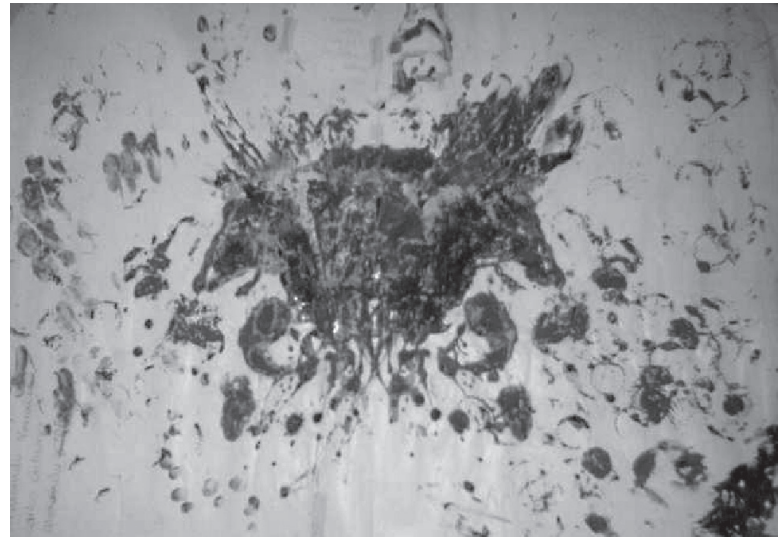

Fotografía 3. Mapa parlante del barrio. Fuente: archivo de investigación.

\section{Discusión}

\section{¿Cómo estas formas de socialización configuran los imaginarios sociales de los niños y niñas?}

Armando Silva (2000: 55) plantea que "el imaginario tiene que ver con el uso e interiorización de los espacios y sus respectivas vivencias, dentro de una intercomunicación social". Para Cornelius Castoriadis (2002: 46), es "la incesante y esencialmente indeterminada creación socio-histórica y psíquica de figuras, formas e imágenes que proveen contenidos significativos y los entreteje en las estructuras simbólicas de la sociedad" y para Habermas (1987: 64) se traduce en

[...]la construcción del mundo externo y del mundo interno a través de la relación con los objetos físicos y sociales que lo rodean. En su mundo externo, los objetos son los perceptibles y manipulables; mientras que en su mundo interno se dan las representaciones a través de las relaciones interpersonales entre el sujeto y los otros, de lo cual se desprende una acción subjetiva en un sistema de normas socialmente reguladas.

Por otra parte, para Friederich Jameson (2000: 45 ) el imaginario es "como la herramienta para construir historia encaminada a asimilar el tipo de colectividad a la cual pertenece; a partir de este proceso de sus propias vidas y experiencias se convierten en el centro, alrededor del cual se desarrolla su historia y su sociedad", que se construyen colectivamente $y$ desde las particulares formas de comprender el mundo y su realidad.

Frente a la relación entre lo que es y lo que se quiere ser, el niño y la niña construyen su imaginario. Las diferentes representaciones en el mundo objetivo y subjetivo muestran aquello que los sujetos y los objetos en la realidad son y que dejan de ser, o "no son"; en otras palabras, la manera como los objetos son percibidos se explica mediante la abstracción, la asimilación, el significado, el significante y la interacción del sujeto y el objeto que se manifiestan al individuo, pero en especial por la manera como este lo asimila, lo vive y lo interpreta expresan su sentido de lo que puede ser, lo que es y a la vez lo que no lo es, sin perder su esencia y existencia. Esa realidad trastocada desde la experiencia empieza a transformarse de acuerdo con el mundo de cada sujeto, quien expresa una realidad y una fantasía (complementarias o antagónicas) que se anhelan o, simplemente, se interpretan.

Para Mead (citada por Ritzer,1993 259):

[...]los símbolos significantes como la suerte del gesto que sólo los humanos son capaces de realizar. Los gestos al surgir de un individuo se convierten en una respuesta deseada por los individuos receptores. La función del 
gesto permite la adaptación de los individuos involucrados en un acto social. El gesto con los símbolos significantes permite el desarrollo del lenguaje y por lo tanto, la capacidad de comunicarse como agentes del pensamiento $e$ interacción simbólica.

Los símbolos reflejados en los dibujos de los niños y niñas evidencian la manera como el sujeto abstrae, entiende e interpreta su mundo tanto objetivo como subjetivo, y esto se descubre en los trazos, las pinturas, los colores y la forma de comunicar lo que significa el dibujo. Es decir, si en la realidad encontramos una manifestación desagradable para el observador, al plasmar esta expresión en un gráfico se observa cómo esta se transforma y se torna en una imagen anhelada por el sujeto, mediante un trabajo creativo e imaginativo para poder lograr lo deseado. Esta capacidad creativa del ser humano no posee un origen extra mundano, sino una experiencia sensorial y racional que se encuentra en el mundo de la vida, en esa cotidianidad que el hombre afronta en su interacción social con su familia, grupo de iguales y barrio. Es decir, desde el imaginario el niño y la niña encuentran su propia manera de mirar e interpretar el mundo, y es allí donde proponen alternativas para transformar su realidad.

Por otro lado, la vida cotidiana, que es entendida como las relaciones que constantemente se crean y se dinamizan en un grupo de individuos, permite fundamentar las comprensiones que las personas hacen de su realidad, lo que para Germán Rey (1986: 13) es "la red de interacciones dentro de un marco de definiciones históricas, es dinámica en la medida en que participa en todos los aspectos de la realidad". Por su parte, Habermas (1987) supone una relación intersubjetiva entre lo que se comprende como vida cotidiana y el mundo de la vida, los cuales se enmarcan en una dialéctica cultural donde los símbolos se convierten en significados esenciales que representan las interacciones a partir de la subjetividad y la objetividad. Los infantes son seres sociales por excelencia: su vida cotidiana va marcada por el contacto con otros grupos, como su familia, su grupo de iguales y su entorno $y$, dentro de aquellos contextos, sus vivencias con el juego, con el trabajo, con sus necesidades y desarrollos cognitivos propios.

La vida cotidiana para un niño y una niña es su referente conceptual, elementos de su conciencia, su visión comunitaria y social. La población infantil aprehende e interioriza el mundo objetivo y subjetivo externo, creando y dinamizando su propio mundo, con la capacidad de imaginar y de solucionar sus necesidades mediante tal ejercicio. Ellos inventan las normas, las reglas y su cotidianidad, las cuales se ven reflejadas en el juego o en sus conversaciones con sus pares, lo cual es la base para que los infantes puedan recrear su mundo y le da significado a sus relaciones sociales, su espacio físico (que se convierte en su ambiente), sus propios sentires y sus creencias. Esta comprensión del mundo es dinámica y es rebelde: reconoce su realidad familiar y vecinal y a la vez la rechaza, creando nuevos modos de vida dentro de estos mismos escenarios. Por ejemplo, sus dinámicas familiares vulnerables las recrea en el juego, buscando satisfacer sus necesidades básicas, convirtiéndose así en una especie de herramienta para la supervivencia. Para Consuelo Corredor (1999: 54): "la vulnerabilidad se asocia a la situación de pobreza que dadas sus carencias, la población está sujeta a mayor dificultad por el riesgo de no poder sobrevivir ante cambios del entorno".

\section{A manera de conclusión}

El imaginario social no atiende a la verdad o falsedad de su contenido, sino a la lógica interna de la estructura a la cual pertenece. La dimensión imaginaria dota de sentido a todos y cada uno de los elementos que la componen, de modo tal que cada significado remite a un sinnúmero de otros significados en un devenir espacio-temporal inagotable. Pero ese imaginario no simplemente se queda en plasmar mediante un dibujo su realidad, sino también en el imaginario de los infantes existen mecanismos o herramientas con las que buscan transformar esa realidad; es 
ahí cuando el niño y la niña se convierten en actores sociales capaces de cambiar, proponer y tener un lugar en la comunidad y la sociedad, lo que se ve reflejado en sus sueños y anhelos, en especial cuando ellos proyectan su vida a futuro, con su anhelo de ser, por ejemplo, policía, militar o médico. Es así como en su vida cotidiana los niños del barrio Niño Jesús de Praga buscan, mediante sus imaginarios, una solución para el consumo y comercialización de sustancias psicoactivas, atraco, madre soltersimo y pandillismo, vivenciado por ellos en el sector, y que se convierte en impedimento para su bienestar y mejor desarrollo integral.

Estos elementos, que van definiendo su mundo, se convierten en un modelo conductual, valorativo y sentimental. Su significado como partícipes de estos contextos los obliga a mantener una posición de asimilación frente a su cultura, pero también de rechazo frente a lo que los cohesiona, y que es posible evidenciar con sus manifestaciones de un "querer ser", definido por el anhelo de adquirir estudios de educación superior y de generar estrategias colectivas para mejorar las condiciones de vida de su barrio, el cual, en últimas, es su territorio.

El infante es a la vez subjetivo y objetivo, es decir, que solo mediante su imaginario puede, internamente, interpretar los comportamientos familiares, de su grupo de iguales y barriales, así como manifestar sus pensamientos $y$ sentimientos de cambio. Esto permite evaluar su visión de mundo , para así buscar su satisfacción, al identificar sus expectativas y las necesidades de su entorno: "solo viéndose a sí mismo como un objeto puede saber cómo controlar, guiar y juzgar su propia conducta y actuar de acuerdo a las expectativas del otro" (Feredick, 1964: 92).

Es entonces, ese deseo futuro y el que es esperado por su familia, grupo de iguales y barrio lo que le permite construir un imaginario del "querer ser", como el más libre y espontáneo que nace a pesar de sus circunstancias económicas y sociales; es decir, tal imaginario no es impuesto, sino que se genera desde sus propias percepciones y sentires frente a su realidad: "Yo en grande quisiera ser policía”, “Yo en grande quisiera ser soldado"; estos testimonios se presentan como el imaginario que emerge a partir de su necesidad, debido a las circunstancias de vulnerabilidad, como el consumo de drogas y las actividades ilícitas de su entorno familiar y barrial.

Ser policía o soldado es "querer ser" para controlar otros elementos que desde su condición actual les es imposible Ser policía o soldado es el ejemplo de dos personalidades que logran ejercer la autoridad y brindar justicia pero, sobre todo, son en ellas quienes pueden cambiar las situaciones que están afectando el bienestar de su comunidad: "Ser policía para sacar a los marihuaneros del barrio ya los ladrones". Entonces, el imaginario llega hasta personificar ese querer desde lo que han asimilado de su entorno "como la vinculación que tiene la fuerza pública en su barrio cuando interviene en capturar a jóvenes consumidores o expendedores de sustancias psicoactivas".

Los infantes han interpretado que existe un medio para controlar la ruptura de su tejido social, que desde sus vecinos y familia no se ha logrado, porque todos han asimilado ese estilo de vida y, por tanto, los niños han experimentado que la única fuerza que aporta para disminuir la problemática social de su entorno es la fuerza pública. Así, han priorizado dos aspectos mencionados: la protección y participación como formas de una construcción alterna de su identidad frente a lo colectivo.

A este imaginario se le suma el "querer ser" médico para darle protección y cuidado a su madre como su principal referente afectivo. Este va cargado de valores de tipo social y colectivo, los cuales se encuentran opacados ominimizados por elementos que desintegran las relaciones entre la comunidad y frente a los otros. Ese es el papel que han asimilado y que deben cumplir para darle bienestar a su comunidad, no tanto por la figura de policía, soldado o médico, sino del papel que cumplen en sus contextos y comunidades. 


\section{Referencias}

Bonilla, E.; Rodríguez. P. (1997). La investigación en ciencias sociales. Más allá del dilema de los métodos, Bogotá: Ediciones Uniandes.

Castoriadis, C. (2002). "El campo de lo social histórico" [en línea], recuperado 15de noviembre de 2003, disponible en: http:// www.hemerodigital.unam.mx

Corredor, C. (1999). Pobreza y desigualdad. Reflexiones y medición, Bogotá: Cinep.

Feredick, E. (1964). El niño y la sociedad, Buenos Aires: Paidós.

Gutiérrez, V. (2005). "Modalidades de familia de fin de siglo", revista Huellas Escritas, núm. 19.

Habermas, J. (1987). Teoría de la acción comunicativa, Madrid: Taurus.

Horlck, E. (1982). Desarrollo del niño, México: McGraw Hill.

Jameson, F. (2000). "La influencia de la violencia en las representaciones delos niños y las niñas del espacio social", en Efectos sociales y culturales del desplazamiento, Bogotá: Universidad Nacional de Colombia.

Martínez, M., Sauri, G. (2004). "Infancia como construcción de alternativas sociales" ponencia presentada en el curso internacional de verano Espacio Social de la infancia, Chile: s.e.

Páez, M. G.(1984). Sociología de la familia: elementos de análisis en Colombia y América Latina, Bogotá: USTA, Centro de Enseñanza Desescolarizada.

Rey, G. (1986). "Las huellas de lo social: socialización y vida cotidiana", presentado en el simposio Investigación Social y Vida Cotidiana, Medellín: Universidad Pontificia Bolivariana.

Ritzer, G. (1993). Teoría sociológica moderna, Madrid: McGraw Hill.

Silva, A. (2000). Imaginarios urbanos (cuarta edición aumentada), Bogotá: Tercer Mundo Editores.

Wagner, W. (1987). Sociología de la modernidad, Barcelona: Herder. 
